ulus. The predictions were always fulfilled, since the animals always turn to their right when stimulated.

In the same way Paramecia always turn toward the aboral side when stimulated. These animals have thus a definite 'motor reaction' to almost any stimulus-consisting of a dart backward and a turning toward a structurally defined side. The collection of the Paramecia in the drop of acid is due to the fact that the passage from the acid to the water acts as a stimulus to produce this 'motor reacton.' This prevents them from leaving the acid, and a dense collection is soon formed.

The collecting of Chilomonads in acetic acid was shown. The essential identity in character of 'positive chemotaxis' or 'positive chemotropism' with 'negative chemotaxis' or 'chemokinesis' was demonstrated by showing that whether we get the one or the other depends on the relative arrangement of the two fluids. If the Paramecia or Chilomonads were in water, and a drop of acid was introduced, a dense group was quickly formed in the acid (' positive chemotaxis'); if on the other hand the organisms are in acid and a drop of water is introduced, the latter remains quite empty. If now the organisms were in water and a drop of salt solution was introduced, the drop remained empty ('negative chemotaxis,' or ' chemokinesis'); if the organisms were in salt solution and a drop of water was introduced, they swarmed into the drop of water, as previously into the acid. Passage from the water to acid does not cause the 'motor reaction,' while passage from the acid to the water does, hence they collect in the acid; passage from the salt solution to the water does not cause the reaction, while passage from the water to the salt does, hence they collect in the drop of water.

Many other demonstrations were given, and the significance of the results in simplifying the 'psychology' of these organisms, and in their relation to current theories of tropisms or taxis was discussed. Similar results to those set forth were stated to have been obtained with certain Metazoa also.

$$
\begin{aligned}
& \text { H. S. Jennings, } \\
& \text { Secretary }
\end{aligned}
$$

\section{DISCUSSTON AND CORRESPONDENCE.}

UNAUTHORIZED NEWSPAPER REPORTS.

IN view of the fact that a number of daily papers have printed reports concerning alleged or real experiments of mine I wish to state :

1. That none of the statements printed in the newspapers have been authorized by me.

2. That whatever I may have to say about my work will be published in scientific journals.

\section{University of Chicago.}

JACQUES LOEB.

\section{AN APPEAL FOR ASSISTANCE.}

To The EnItor of ScIEnce: A letter received from Mr. R. W. Garner, dated from Sao Thomé, West Africa, November 26, 1900, gives rather painful news of that intrepid explorer in the jungles of West Africa. Relying upon his remarkable powers of endurance and his simple habits of life, Mr. Garner started on this expedition with very limited means and an inadequate outfit. It seems that on this occasion he was overcome by the jungle fever, and the unexpected expense incurred by a month's sickness has exhausted his resources. He does not ask for help, but states that since he is already in a country where few men would care to venture, it seems as if some institution might like to send him a moderate sum of money, in return for which he would collect ethnological and zoological material, and at the same time could continue his own investigations. This is certainly a good opportunity, and any institution that can take advantage of it would at the same time be rendering assistance to a worthy explorer who is deserving of help in his undertaking. It will be necessary to secure Mr. Garner's services at once, since it is evident that if he does not receive some substantial cooperation, he cannot continue his researches. Any communication should be sent direct to Mr. R. W. Garner at Sao Thomé, West Africa. F. W. Putnam.

Peabody Museum of archelogy and Ethology, Harvard University, Cambridge, Mass.

CURRENT NOTES ON MIETEOROLOGY.

RAINFALL OF NEW SOUTH WALES.

THE 'Results of Rain, River, and Evaporation Observations made in New South Wales 